\title{
PRODUC̃̃O DE MUDAS DE ESSÊNCIAS FLORESTAIS EM DIFERENTES SUBSTRATOS E ACOMPANHAMENTO DO DESENVOLVIMENTO EM CAMPO
}

\author{
Yield of seedling species forestry of four using different substrates and development in field
}

\author{
Rone Batista de Oliveira ${ }^{1}$, Julião Soares de Souza Lima ${ }^{2}$, \\ Carlos Alberto Martinelli de Souza ${ }^{3}$, Samuel de Assis Silva ${ }^{4}$, Sebastião Martins Filho ${ }^{5}$
}

\begin{abstract}
RESUMO
Objetivou-se neste trabalho avaliar o efeito de substratos com diferentes características físicas e químicas na formação de mudas e o desenvolvimento no campo das espécies Cedrela fissilis Vell. (cedro rosa), Eucalyptus grandis W. Hill ex Maiden (eucalipto), Acacia holocericea A. Cunn. ex G. Don (acácia) e Schinus terebinthifolius Raddi (aroeirinha), produzidas em tubetes de $55 \mathrm{~cm}^{3}$. Os substratos no viveiro foram constituídos de diversas combinações dos seguintes materiais: húmus de minhoca, esterco bovino curtido, esterco de galinha, turfa, casca de amendoim processada, casca de arroz carbonizada e palha de café. Na primeira etapa foi utilizado o delineamento inteiramente casualizado (DIC). Foram avaliadas as variáveis morfológicas das mudas e suas relações. O delineamento estatístico no campo foi em blocos, em parcelas subdivididas e as covas foram preenchidas com dois diferentes tipos de adubações - esterco bovino e esterco bovino + condicionador de solo. Nessa etapa, foram avaliadas as variáveis altura e diâmetro das plantas. Os dados foram submetidos à análise de variância e ao teste de média (Newman-Keuls 5\%). Conforme os resultados obtidos na etapa de viveiro, os substratos que podem ser recomendados para produção de mudas das espécies estudadas foram os à base de Húmus de minhoca, casca de amendoim processada e turfa. Na etapa de campo, a adubação com esterco bovino + condicionador de solo proporcionou maiores valores das variáveis em todas as espécies, com exceção da altura das plantas para a acácia.
\end{abstract}

Termos para indexação: Viveiro, qualidade de mudas, desempenho pós-plantio.

\begin{abstract}
This experiment was installed with the aim of evaluating the substrates effect with different chemical and physical characteristics in the formation of seedling of Cedrela fissilis Vell. (cedro rosa), Eucalyptus grandis W. Hill ex Maiden (eucalipto), Acacia holocericea A. Cunn. ex G. Don (acacia) and Schinus terebinthifolius Raddi (aroeirinha) produced in tubes of $55 \mathrm{~cm}^{3}$. The substrates had been constituted of several combinations of the following materials: húmus of earthworm, tanned cattle manure, fertilizer of hen, turf, rind of processed peanut, carbonized rind of rice, coffee straw. The experimental outline used was entirely randomized. The morphologic parameters of seedling and their relations were evaluated. The pits were filled with two types of fertilization: cattle manure and cattle manure + conditioning of soil in field. The data were submitted to the analysis of variance and the test of average (Newman-Keuls $5 \%$ ). The results obtained in the nursery stage that can be recommended for production of seedlings of the studied essences were the base substrates of earthworm humus, peanut peel processed and peat. In the field stage, except for the species acacia, for the variable height of the plants, the fertilization with cattle manure + conditioning of soil was the best for all the appraised variables, providing better development of the seedlings in relation to the fertilization with cattle manure only.
\end{abstract}

Index terms: Nursey, seedling quality, post-planting performance.

\section{(Recebido em 22 de junho de 2005 e aprovado em 15 de março de 2007)}

\section{INTRODUÇÃo}

Em razão da tendência de ocupação de terras com futuros plantios florestais de forma equilibrada, faz-se necessário produzir, avaliar e selecionar substratos de fácil aquisição e que atenda às exigências das espécies.
A demanda por produtos de origem florestal aumentou sensivelmente nas últimas décadas, levando a silvicultura a buscar alternativas que pressupõem altas produtividades (BOLFE et al., 2004).

\footnotetext{
${ }^{1}$ Engenheiro Agrônomo, Doutorando em Agronomia - Departamento de Engenharia Rural - Universidade Estadual Paulista/UNESP - Rua Doutor José Barbosa de Barros - Jardim Paraíso - 18610-307 - Botucatu, SP - rbatista@fca.unesp.br

${ }^{2}$ Doutor em Mecanização Agrícola, Professor Adjunto IV - Departamento de Engenharia Rural - Universidade Federal do Espírito Santo/UFES - Centro de Ciências Agrárias - Cx. P. 16 - 29500-000 - Alegre, ES - limajss@.yahoo.com.br

${ }^{3}$ Engenheiro Florestal, Doutorando em Engenharia Florestal - Universidade Federal de Santa Maria/UFES - Campus Universitário, Prédio 44 - Camobi 97105-900 - Alegre, ES - camartinelli5@hotmail.com

${ }^{4}$ Engenheiro Agrônomo, Mestrando em Produção Vegetal - Departamento de Engenharia Rural - Universidade Federal do Espírito Santo/UFES - Centro de Ciências Agrárias - Cx. P. 16 - 29500-000 - Alegre, ES - charcate@hotmail.com

${ }^{5}$ Engenheiro Agrônomo, Ph. D. em Estatística, Professor Adjunto IV - Universidade Federal de Viçosa/UFV - Avenida Peter Henry Rolfs, s/n - Campus

Universitário - 36570-000 - Viçosa, MG - martinsfilho@pq.cnpq.br
} 
A demanda cada vez maior por mudas de espécies florestais a um menor custo fez com que a qualidade das mudas fosse relegada a segundo plano (GOMES et al., 1991).

De acordo com Gonçalves \& Poggiani (1996), a boa formação de mudas destinadas à implantação de povoamentos florestais para a produção de madeira e de povoamentos mistos para fins de preservação ambiental e/ou, recuperação de áreas degradadas, está relacionada com o nível de eficiência dos substratos. A germinação de sementes, a iniciação do crescimento radicular e da parte aérea está associada à boa capacidade de aeração, drenagem, retenção e disponibilidade de água apresentada pelos substratos. Essas características são altamente correlacionadas entre si, as duas primeiras estão diretamente relacionadas com a macroporosidade, enquanto retenção de água e os nutrientes estão relacionados com a microporosidade e superfície específica do substrato.

Diversos materiais de origem vegetal e animal têm sido utilizados no preparo de compostos orgânicos para produção de mudas. A escolha do substrato, quando da sua formulação, deve ser feita em função da disponibilidade de materiais, suas características físicas e químicas, seu peso e custo (TOLEDO, 1992). É necessário, portanto, testar substratos de fácil aquisição, alternativos a vermiculita, por ser essa de elevado custo (GOMES et al., 1991).

Um dos principais questionamentos realizados pelos técnicos envolvidos na recuperação de ecossistemas degradados refere-se à escolha das espécies que deverão ser plantadas. As principais características desejáveis são espécies vegetais com capacidade para crescer rapidamente, proteger e enriquecer o solo, abrigar e alimentar a fauna, recompor a paisagem e estabelecer o regime de água no solo (DAVIDE, 1994).

Segundo Faria et al. (1997), o plantio de espécies arbóreas e o acompanhamento do seu desenvolvimento através de medições periódicas são, portanto, importantes no sentido de balizar a escolha das espécies e a melhor forma de plantá-las. Objetivou-se aqui, avaliar, sob condições de viveiro os efeitos de diferentes substratos no desenvolvimento de quatro essências florestais e verificar a qualidade e o desempenho pós-plantio das mesmas.

\section{MATERIAL E MÉTODOS}

Este experimento foi conduzido no Centro de Ciências Agrárias da Universidade Federal do Espírito Santo, no município de Alegre-ES, situado a $20^{\circ} 45^{\prime} 48^{\prime \prime}$ de latitude Sul e 41'31'57'” de longitude Oeste de Greenwich, altitude de aproximadamente 150 metros. O clima predominante é verão quente e úmido e inverno seco, com uma precipitação anual média de $1200 \mathrm{~mm}$ e temperatura média anual de $23^{\circ} \mathrm{C}$, com máximas diárias de $29^{\circ} \mathrm{C}$ e mínimas de $20^{\circ} \mathrm{C}$ (ESPÍRITO SANTO, 1994).

O experimento foi conduzido em duas etapas: produção de mudas e desenvolvimento no campo. Em decorrência do atual uso em reflorestamentos, recuperação de áreas degradadas e pela importância econômica que vem exercendo na região, as espécies florestais utilizadas foram: Schinus terebinthifolius Raddi (aroeirinha) da família Anacardiacea; Cedrela fissilis Vell. (cedro rosa) da família Meliaceae; Eucalyptus grandis W. Hill ex Maiden (eucalipto) da família Myrtaceae; e Acacia holocericea (acácia), da família Fabaceae-Mimosoideae.

Para a produção de mudas foram utilizados tubetes de seção circular com capacidade volumétrica de $55 \mathrm{~cm}^{3}$, preenchidos com os diferentes substratos que apresentamse na Tabela 1 .

Para a caracterização dos substratos foi usada a metodologia proposta por Gonçalves \& Poggiani (1996). A densidade de partículas (Dp) foi determinada pelo método do balão volumétrico e a densidade aparente (Da) pelo método da proveta (EMBRAPA, 1997), ambas determinadas no laboratório de física do solo do CCA-UFES. A porosidade total $(\mathrm{Pt})$ foi determinada pela expressão: $\mathrm{Pt}(\%)=[(\mathrm{Dp}-$ $\mathrm{Da}) / \mathrm{Dp}]^{*} 100$.

A macroporosidade (Mac) foi determinada pela seguinte equação:

$$
\operatorname{Mac}(\%)=\frac{\left[\frac{\operatorname{Pt}(\%) * 50 \mathrm{~cm}^{3}}{100}-\text { Agua }_{\text {retida }}\right]}{50 \mathrm{~cm}^{3}} * 100
$$

em que Água ${ }_{\text {retida }}$, é a água retida pelo substrato em tubetes de $55 \mathrm{~cm}^{3}$ de volume útil. A retenção de água foi obtida ao saturar o substrato dentro do tubete, com água, e ao pesar o substrato úmido após 24 horas. Em seguida, secou-se o substrato $\left(105^{\circ} \mathrm{C}\right.$, por 24 horas) e subtraiu-se a massa úmida da massa seca, obtendo-se a água retida, que multiplicada pela densidade da água dá o volume de água retida, conforme Moraes Neto et al. (2001).

$\mathrm{Na}$ primeira etapa do experimento as variáveis avaliadas foram: altura da parte aérea, diâmetro do colo, massa seca total, massa seca da raiz e relação da parte aérea com o diâmetro do colo. Na segunda, para avaliar o desenvolvimento das mudas no campo, foi utilizada uma área cujo solo é classificado como latossolo vermelhoamarelo e que anteriormente estava sendo utilizado como 
Tabela 1 - Composição dos substratos utilizados para a produção de mudas das espécies.

\begin{tabular}{|c|c|}
\hline Substratos & Composição $^{1}$ \\
\hline 1 & CAC 50\% + EG 40\% + TB 3\% + A 7\% + Fertilizante ${ }^{3 /}+$ Calcário \\
\hline 2 & CAC $30 \%+$ EB $60 \%+$ TB 3\% + A 7\% + Fertilizante + Calcário \\
\hline 3 & CAP $25 \%+$ HM $35 \%+$ T 30\% + TB 3\% + Fertilizante + Calcário \\
\hline 4 & CAP $30 \%+$ HM $60 \%+$ TB 3\% + A 7\% + Fertilizante + Calcário \\
\hline 5 & AP $30 \%+$ EB $60 \%+$ TB $13 \%+$ A 7\% + Fertilizante + Calcário \\
\hline 6 & ${ }^{2 /}$ Plantmax \\
\hline
\end{tabular}

pastagem. No preparo do solo para o plantio realizou-se uma roçagem mecânica.

Aos 95 dias após a semeadura, as mudas foram plantadas em covas abertas manualmente no espaçamento de $1,50 \times 1,50 \mathrm{~m}$ com dimensões $20 \times 20 \times 20 \mathrm{~cm}$ e preenchidas com $1 / 3$ de terra e dois diferentes tipos de adubação: com esterco bovino e com esterco bovino mais 8 gramas de condicionador de solo. No plantio, buscou-se padronizar a altura e o diâmetro das mudas para que nenhum tratamento fosse beneficiado. O condicionador de solo utilizado é um produto granulado à base de polímeros sintéticos e sais de acrilato, não poluente, muito absorvente, e quando se adiciona água ele expande formando um gel viscoso, insolúvel, podendo aumentar em até 400 vezes seu peso em água e, portanto, manter a umidade do solo por um tempo maior.

Em campo, as espécies foram avaliadas mensalmente até o quinto mês a partir do plantio quanto à sobrevivência, a altura das plantas e o diâmetro do colo. Os tratos culturais envolveram o combate à formigas cortadeiras, limpeza (capina) e irrigação.

$\mathrm{Na}$ primeira etapa, o delineamento estatístico utilizado foi o inteiramente casualizado, em fatorial 6 x 4 (6 substratos $\mathrm{x} 4$ espécies). $\mathrm{O}$ experimento foi conduzido com 24 tratamentos (combinação de fatores), e com quatro repetições, com uma planta por tubete. Na etapa de campo, o delineamento estatístico foi em blocos casualizados, em parcelas subdivididas com cinco repetições, com uma planta por parcela.

\section{RESULTADOS E DISCUSSÃO}

As características químicas e físicas dos substratos utilizados na produção de mudas apresentam-se na Tabela 2.
Observa-se que os substratos 2, 3 e 6 apresentam comportamentos semelhantes quanto aos teores de matéria orgânica, com maior valor verificado no substrato 06 , porque sua composição possui vermiculita e casca de pinus moída e enriquecida. Verifica-se que os substratos apresentam diferentes características químicas e físicas em função de suas composições, refletindo-se nos valores das variáveis avaliadas no desenvolvimento das espécies florestais no viveiro.

Para a aroeirinha (Tabela 3), o diâmetro do colo não apresenta diferença significativa entre os substratos $1,2 \mathrm{e}$ 5 , apresentando os maiores valores para os substratos 3,4 e 6; a altura das plantas nos substratos 1,2 e 5, com maior crescimento, apresentaram diferença significativa em relação aos substratos 3,4 e 6; para a massa seca da raiz não houve diferença significativa entre os substratos 1 e 5 com menor valor para o substrato 5, provavelmente pela maior proporção de raízes finas observada nesse substrato, resultado também obtido por Toledo (1992).

Para acácia o diâmetro do colo não apresenta diferença significativa entre os substratos 3,4 e 6 , apresentando maior valor para o substrato 4 e menor para o substrato 2; a altura das plantas no substrato 3 apresenta diferença significativa em relação aos demais, apresentando maior crescimento; a massa seca da raiz não apresenta diferença significativa entre os substratos 3 e 4 , com maior valor para o substrato 3. Na relação altura/ diâmetro do colo, o substrato 2 apresenta diferença significativa em relação aos demais, apresentando o maior valor. Os substratos 3 e 4 apresentaram melhores condições para o crescimento e desenvolvimento dessa espécie. Esse fato é explicado pelos valores das características retenção de água, matéria orgânica, teores de densidade do solo e, 
Tabela 2 - Características físicas e químicas dos substratos utilizados no estudo.

\begin{tabular}{lcccccc}
\hline \multicolumn{1}{c}{ Características } & \multicolumn{5}{c}{ Substratos } \\
\cline { 2 - 7 } & 01 & 02 & 03 & 04 & 05 & 06 \\
\hline Densidade aparente $\left(\mathrm{g} \mathrm{cm}^{-3}\right)$ & 0,50 & 0,52 & 0,63 & 0,58 & 0,35 & 0,34 \\
Densidade de partículas $\left(\mathrm{g} \mathrm{cm}^{-3}\right)$ & 1,86 & 1,78 & 1,67 & 2,35 & 1,72 & 1,60 \\
Porosidade total $(\%)^{1 /}$ & 73,12 & 70,79 & 63,37 & 75,32 & 79,65 & 78,75 \\
Macroporosidade $(\%)^{1 /}$ & 31,42 & 21,02 & 6,78 & 15,76 & 36,65 & 16,95 \\
Microporosidade $(\%)^{1 /}$ & 41,70 & 49,77 & 56,59 & 59,56 & 43,00 & 61,81 \\
Retenção de $\mathrm{H}_{2} \mathrm{O}\left(\mathrm{ml}^{1 /} \mathrm{cm}^{-3}\right)$ & 20,85 & 24,88 & 28,30 & 29,78 & 21,45 & 22,43 \\
$\mathrm{H}+\mathrm{Al}\left(\mathrm{cmol}_{\mathrm{c}} \mathrm{dm}^{-3}\right)$ & 2,30 & 3,00 & 1,90 & 14,00 & 2,30 & 15,90 \\
$\mathrm{P}$ disponível $\mathrm{mg} \mathrm{dm}^{-3}$ & 126,0 & 165,0 & 192,0 & 86,00 & 324,0 & 140 \\
$\mathrm{~K}$ trocável $\mathrm{mg} \mathrm{dm}^{-3}$ & 3605 & 1681 & 880 & 600 & 1155 & 480 \\
Ca trocável $\left(\mathrm{cmol}_{\mathrm{c}} \mathrm{dm}^{-3}\right)$ & 4,00 & 11,50 & 9,40 & 11,50 & 5,00 & 12,00 \\
Mg trocável $\left(\mathrm{cmol}_{\mathrm{c}} \mathrm{dm}^{-3}\right)$ & 3,50 & 4,10 & 2,80 & 4,10 & 2,80 & 8,00 \\
CTC efetiva $\left(\mathrm{cmol}_{\mathrm{c}} \mathrm{dm}^{-3}\right)$ & 17,23 & 17,40 & 16,70 & 17,40 & 11,00 & 21,23 \\
Matéria orgânica total $\left(\mathrm{g} \mathrm{kg}^{-1}\right)^{2 /}$ & 276 & 320 & 320 & 357 & 205 & 327 \\
\hline
\end{tabular}

1/ Análises realizadas segundo a metodologia proposta por Gonçalves \& Poggiani (1996); ${ }^{2 / A n a ́ l i s e s ~ r e a l i z a d a s ~ s e g u n d o ~ a ~ m e t o d o l o g i a ~}$ apresentada por Kihel (1985), valores em termos de base seca a $105^{\circ} \mathrm{C}$, para facilitar as comparações.

conseqüentemente, a proporção de macroporos, proporcionando uma aeração adequada dos substratos e desenvolvimento do sistema radicular. Esses substratos apresentaram uma porcentagem de microporos considerada adequada (55-60\%), segundo padrão definido por Gonçalves \& Poggiani (1996), conferindo a esse substrato uma capacidade de retenção de água satisfatória.

O diâmetro do colo, para as mudas de eucalipto não apresenta diferença significativa entre os substratos avaliados. As plantas provenientes dos substratos 3 e 5 apresentam maior crescimento em altura; a relação altura/ diâmetro do colo não apresenta diferença significativa entre os substratos 1 e 2, porém, diferença significativa entre os demais. Conforme observado por Gomes et al. (2002), a relação altura/diâmetro do colo, apresenta uma boa contribuição para uma avaliação da qualidade de mudas de Eucalyptus grandis (eucalipto), sendo essas características fáceis e viáveis de mensuração, além de não destruir as mudas.

O diâmetro do colo das mudas de cedro rosa (Tabela 3) apresenta o menor valor no substrato 1 e diferença significativa entre os demais; a altura das plantas nos substratos 1, 2, 4 e 5 apresenta maior crescimento e diferença significativa em relação aos substratos 3 e 6; o maior valor de massa seca total apresenta-se no substrato 4, com densidade aparente de $0,58 \mathrm{~g} \mathrm{~cm}^{-3}$, concordando com o observado por Moraes Neto et al. (2001).

Em geral, observa-se que o substrato 1 não apresentou condições favoráveis para as espécies na característica diâmetro do colo. Esse fato é devido aos menores valores de retenção de água e sua composição com casca de arroz carbonizada, que segundo Guerrini \& Tirgueiro (2004) é um material pobre em nutrientes, apresentando apenas o teor de $\mathrm{K}\left(\mathrm{K}_{2} \mathrm{O}\right)$ mais elevado.

$\mathrm{Na}$ Figura 1, observam-se os resultados das variáveis avaliadas nas espécies florestais em campo. Em geral, as avaliações da altura e do diâmetro do colo entre uma mesma espécie, apresentam diferença significativa em função das duas adubações, com exceção da acácia, para a altura das plantas. $\mathrm{O}$ maior crescimento em diâmetro de colo e altura de planta, demonstrado pela adubação com esterco de boi + condicionador de solo (EB + CS) está associado à ação e influência do gel condicionador de solo (pela sua atividade de expansão e retração) presente nessa adubação, sendo esse o único fator que diferenciava para as plantas. Segundo Azevedo et al. (2002), estudando a eficiência do condicionador de solo (CS) no fornecimento de água para o cafeeiro, constatou que o efeito do polímero sobre as características estudadas foi significativo, podendo-se afirmar que a presença do CS no substrato permite ampliar os intervalos entre irrigações, sem comprometer o crescimento da planta por déficit de água, além de afirmar que, quanto menor o fornecimento de água, maior a importância do polímero. Wofford Junior (1992) destaca que as raízes das plantas crescem por dentro dos grânulos do polímero hidratado, havendo um grande desenvolvimento de pêlos radiculares, proporcionando maior superfície de contato das raízes com a fonte de água 
OLIVEIRA, R. B. de et al.

Tabela 3 - Diâmetro do colo, altura de plantas, massa seca de raiz, massa seca total, relação altura/diâmetro do colo das mudas das espécies florestais em diferentes substratos.

\begin{tabular}{|c|c|c|c|c|c|}
\hline Substratos & Diâmetro do colo & Altura & $\begin{array}{c}\text { Massa } \\
\text { seca da raiz }\end{array}$ & Massa seca total & $\begin{array}{c}\text { Altura/ } \\
\text { Diâmetro do colo }\end{array}$ \\
\hline & $\mathrm{mm}$ & $\mathrm{cm}$ & $\mathrm{g}$ & $\mathrm{g}$ & $\mathrm{cm} \mathrm{mm}^{-1}$ \\
\hline \multicolumn{6}{|c|}{ Schinus terebinthefolius (aroeirinha) } \\
\hline 1 & $0,69 \mathrm{~b}$ & $19,55 \mathrm{a}$ & $1,31 \mathrm{~b}$ & $2,99^{1 /}$ & $32,06 \mathrm{~b}$ \\
\hline 2 & $0,31 \mathrm{~b}$ & $17,36 \mathrm{a}$ & $1,37 \mathrm{a}$ & 2,98 & $77,40 \mathrm{a}$ \\
\hline 3 & $0,96 \mathrm{a}$ & $15,27 \mathrm{~b}$ & $1,36 \mathrm{a}$ & 3,01 & $16,15 \mathrm{~b}$ \\
\hline 4 & $0,96 \mathrm{a}$ & $14,66 \mathrm{~b}$ & $1,38 \mathrm{a}$ & 3,01 & $16,09 \mathrm{~b}$ \\
\hline 5 & $0,69 \mathrm{~b}$ & $15,47 \mathrm{a} \mathrm{b}$ & $1,27 \mathrm{~b}$ & 2,85 & $23,80 \mathrm{~b}$ \\
\hline 6 & $1,00 \mathrm{a}$ & $14,63 \mathrm{~b}$ & $1,35 \mathrm{a}$ & 2,91 & $14,96 \mathrm{~b}$ \\
\hline \multicolumn{6}{|c|}{ Acacia holocericeae (acácia) } \\
\hline 1 & $0,33 \mathrm{~b}$ & $18,17 \mathrm{~b}$ & $1,32 \mathrm{~b}$ & $2,97^{1 /}$ & $66,45 \mathrm{~b}$ \\
\hline 2 & $0,11 \mathrm{~b}$ & $12,75 \mathrm{c}$ & $1,31 \mathrm{~b}$ & 2,88 & $116,25 \mathrm{a}$ \\
\hline 3 & $0,87 \mathrm{a}$ & $21,75 \mathrm{a}$ & $1,40 \mathrm{a}$ & 3,22 & $25,66 \mathrm{c}$ \\
\hline 4 & $1,17 \mathrm{a}$ & $14,75 \mathrm{bc}$ & $1,37 \mathrm{ab}$ & 3,02 & $13,05 \mathrm{c}$ \\
\hline 5 & $0,37 \mathrm{~b}$ & $13,0 \mathrm{c}$ & $1,32 \mathrm{~b}$ & 2,86 & $49,27 \mathrm{~b}$ \\
\hline 6 & $1,08 \mathrm{a}$ & $16,0 \mathrm{bc}$ & $1,29 \mathrm{~b}$ & 2,88 & $15,85 \mathrm{c}$ \\
\hline \multicolumn{6}{|c|}{ Eucalyptus grandis (eucalipto) } \\
\hline 1 & $0,15^{1 /}$ & $18,25 \mathrm{~b}$ & $1,25^{1 /}$ & $2,76^{1 /}$ & $122,42 \mathrm{a}$ \\
\hline 2 & 0,16 & $18,25 \mathrm{~b}$ & 1,35 & 2,92 & $123,60 \mathrm{a}$ \\
\hline 3 & 0,31 & $24,25 \mathrm{a}$ & 1,29 & 2,94 & $78,26 \mathrm{~b}$ \\
\hline 4 & 0,50 & $19,75 \mathrm{~b}$ & 1,28 & 2,86 & $39,33 \mathrm{c}$ \\
\hline 5 & 0,30 & $21,25 \mathrm{a}$ & 1,26 & 2,74 & $74,79 \mathrm{~b}$ \\
\hline 6 & 0,57 & $18,25 \mathrm{~b}$ & 1,32 & 2,90 & $31,72 \mathrm{c}$ \\
\hline \multicolumn{6}{|c|}{ Cedrela fissilis (cedro rosa) } \\
\hline 1 & $0,98 \mathrm{~b}$ & $15,25 \mathrm{a}$ & $1,25^{1 /}$ & $2,67 \mathrm{~b}$ & $16,08 \mathrm{a}$ \\
\hline 2 & $1,43 \mathrm{a}$ & $14,75 \mathrm{a}$ & 1,28 & $2,72 b$ & $11,14 \mathrm{a}$ \\
\hline 3 & $1,81 \mathrm{a}$ & $11,25 \mathrm{~b}$ & 1,29 & $2,72 b$ & $6,23 b$ \\
\hline 4 & $2,04 \mathrm{a}$ & $17,12 \mathrm{a}$ & 1,29 & $2,97 \mathrm{a}$ & $8,52 \mathrm{~b}$ \\
\hline 5 & $1,91 \mathrm{a}$ & $15,75 \mathrm{a}$ & 1,31 & $2,79 b$ & $10,06 \mathrm{a}$ \\
\hline 6 & $1,68 \mathrm{a}$ & $12,30 \mathrm{~b}$ & 1,25 & $2,66 \mathrm{~b}$ & $7,69 \mathrm{~b}$ \\
\hline
\end{tabular}

As médias seguidas pela mesma letra, em coluna, para cada parâmetro analisado não diferem entre si, pelo teste de Newmans Keuls, $(\mathrm{p}<0,05) .{ }^{1 /}$ Não significativo pelo teste F, $(\mathrm{p}<0,05) .1$ - substrato a base de casca de arroz carbonizada $(50 \%)$ e esterco de galinha (40\%); 2 - substrato a base de casca de arroz carbonizada (30\%) e esterco bovino (60\%); 3 - substrato a base de casca de amendoim processada (25\%), húmus de minhoca (35\%), turfa (30\%); 4 - substrato a base de casca de amendoim processada (30\%), húmus de minhoca (60\%); 5 - substrato a base de acículas de pinus (30\%), esterco bovino (60\%); 6 - produto comercial constituído de composto orgânico de casca de pinus sp.

e nutrientes, facilitando a sua absorção. Wofford Junior \& Koski (1990) constataram aumento no índice de sobrevivência de mudas florestais com o uso de CS, no momento do transplantio e semeio, além de acelerar o crescimento dessas plantas pelo maior suprimento e disponibilidade de água.

O maior incremento proporcionado pela adição do condicionador de solo ao esterco bovino foi para a espécie eucalipto, correspondendo a $62,49 \%$ e $77,77 \%$ para altura das plantas e diâmetro do colo, respectivamente. Segundo Souza et al. (2006), o diâmetro do colo e a altura são fundamentais para a avaliação do potencial de sobrevivência e crescimento no pós-plantio de mudas de espécies florestais. Segundo esses autores, dentro de uma mesma espécie, as plantas com maior diâmetro apresentam maior sobrevivência, por apresentarem capacidade de formação e de crescimento de novas raízes. 

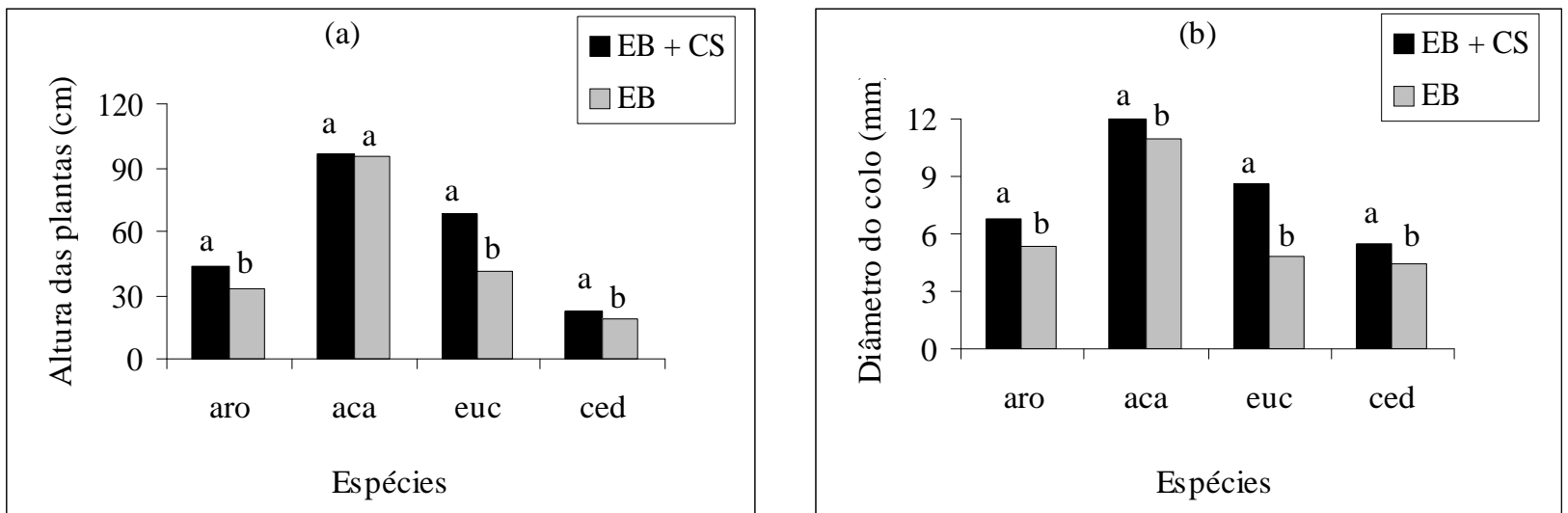

Figura 1 -Altura das plantas (a) e diâmetro das espécies florestais (b): aroeirinha (aro), acácia (aca), eucalipto (euc) e cedro (ced), estudadas em campo com dois tipos de adubação com cinco meses após plantio. A médias seguidas de mesma letra, não diferem entre si pelo teste de Newmans - Keus ( $<$ < 0,05). EB + CS - esterco bovino e condicionador de solo; EB - esterco bovino isolado.

Para o cedro rosa o crescimento em altura das plantas foi menor em relação às demais espécies. Esse fato pode ter ocorrido por se tratar de uma planta secundária, que exige melhor condição de sombreamento para o seu desenvolvimento. $\mathrm{O}$ incremento no crescimento em diâmetro foi de $18 \%$ e a altura de $15 \%$, com adição do condicionador de solo, resultado semelhante encontrado por Souza et al. (2006).

A espécie acácia apresenta maior altura e diâmetro em relação às demais espécies, independente da adubação utilizada (Figura 1). Silva et al. (1997), relatam que algumas espécies apresentam maior taxa de crescimento, por absorverem maior quantidade de nutrientes para atender à sua demanda nutricional, o que, em última análise, permite expressar o potencial de produção de biomassa, na fase inicial de crescimento.

\section{CONCLUSÕES}

Os substratos 3 e 4 , compostos à base de húmus de minhoca, casca de amendoim processada e turfa são os recomendados para a produção de mudas das espécies florestais, na condição do estudo.

A adubação com esterco bovino + condicionador de solo proporcionou maiores valores das variáveis em todas as espécies, com exceção da altura das plantas para a acácia.

\section{AGRADECIMENTOS}

- Ao CNPq pela bolsa concedida;
- A senhores revisores pelas sugestões e comentários, que muito contribuíram para melhoria e qualidade do trabalho.

\section{REFERÊNCIAS BIBLIOGRÁFICAS}

AZEVEDO, T. L. F.; BERTONHA, A.; GONÇALVES, A. C. A. Uso de hidrogel na agricultura. Revista do programa de Ciências Agro-ambientais, Alta Floresta, v. 1, n. 1, p. 2331, 2002.

BOLFE, E. L.; PEREIRA, R. S.; MADRUGA, P. R. A.; FONSECA, E. L. Avaliação da classificação digital de povoamentos florestais em imagens de satélite através de índices de Acurácia. Revista Árvore, Viçosa, v. 28, n. 1, p. 85-90, 2004.

DAVIDE, A. C. Seleção de espécies vegetais para recuperação de áreas degradadas. In: SIMPÓSIO SULAMERICANO, 1.; SIMPÓSIO NACIONAL DE RECUPERAÇÃO DE ÁREAS DEGRADADAS, 2., 1994, Foz do Iguaçu. Anais... Curitiba: Fudef, 1994. p. 111-112.

\section{EMPRESA BRASILEIRA DE PESQUISA} AGROPECUÁRIA. Manual de métodos de análise de solo. 2. ed. rev. e atual. Rio de Janeiro, 1997.

ESPÍRITO SANTO. Secretaria de Estado de Ações Estratégicas e Planejamento. Departamento Estadual de Estatística. Informações municipais do Estado do Espírito Santo 1994. Vitória, 1994. v. 1, 803 p. 
FARIA, J. M. R.; DAVIDE, A. C.; BOTELHO, S. A. Comportamento de espécies florestais em área degradada com duas adubações de plantio. Cerne, Lavras, v. 3, n. 1, p. 25-44, 1997.

GOMES, J. M.; COUTO, L.; BORGES, R. C. G.; FONSECA, E. P. Efeitos de diferentes substratos na produção de mudas de Eucalyptus grandis W.Hill ex Maiden, em "Win-Strip". Revista Árvore, Viçosa, v. 15, n. 1, p. 35-41, 1991.

GOMES, J. M.; COUTO, L.; LEITE, H. G.; XAVIER, A.; GARCIA, S. L. R. Parâmetros morfológicos na avaliação da qualidade de mudas de Eucalyptus grandis. Revista Árvore, Viçosa, v. 26, n. 4, p. 515-523, 2002.

GONÇALVES, J. L. M.; POGGIANI, F. Substratos para produção de mudas florestais. In: CONCRESSO LATINO AMERICANO DE CIÊNCIA DO SOLO, 13., 1996, Águas de Lindóia. Anais... Águas de Lindóia: USP-ESALQ/SBCS/ CEA/SLACS/SBM, 1996. CD-ROM.

GUERRINI, I. A.; TRIGUEIRO, R. M. Atributos físicos e químicos de substratos compostos por biossólidos e casca de arroz carbonizada. Revista Brasileira de Ciências do Solo, Campinas, v. 28, p. 1069-1076, 2004.

KIEHL, E. J. Fertilizantes orgânicos. São Paulo: Pioneira, 1985. $492 \mathrm{p}$.
MORAES NETO, S. P.; GONÇALVES, M. L. J.; SOUZA NETO, M. P. Produção de mudas de seis espécies arbóreas, que ocorrem nos domínios da floresta atlântica, com diferentes substratos de cultivo e níveis de luminosidade. Revista Árvore, Viçosa, v. 25, n. 3, p. 277-287, 2001.

SILVA, I. R.; FURTINI NETO, A. E.; CURI, N.; VALE, F. R. Crescimento inicial de quatorze espécies florestais nativas em resposta à adubação potássica. Pesquisa Agropecuária Brasileira, Brasília, v. 32, n. 2, p. 205-212, fev. 1997.

SOUZA, C. A. M.; OLIVEIRA, R. B.; MARTINS FILHO, S.; LIMA, J. S. Desenvolvimento em campo de espécies florestais em diferentes condições de adubação. Ciência Florestal, [S.1.], v. 16, n. 3, p. 243-249, 2006.

TOLEDO, A. R. M. Efeito de substratos na formação de mudas de laranjeira (Citrus sinensis (L.) OSBECK cv. "Pêra Rio") em vaso. 1992. 88 f. Dissertação (Mestrado em Fitotecnia) - Escola Superior de Agricultura de Lavras, Lavras, 1992.

WOFFORD JUNIOR, D. J. Worldwide research suggestions for cross-linked polyacrilamide in agriculture. 1992. Disponível em: <http:// www.hydrosource.com>. Acesso em: 28 Apr. 2007.

WOFFORD JUNIOR, D. J.; KOSKI, A. J. A polymer for the drought years. 1990. Disponível em: <http:// kimberly.ars.usda.gov>. Acesso em: 28 Apr. 2007. 